\title{
RESEARCH ON CORRELATION AMONG DIFFERENT OSSIFICATION CENTRES IN FEMALE
}

\author{
Golakoti Sree Rama Krishna Gangadhara Ranga Rao1, P. Phani Kiran², G. K. V. Prasad ${ }^{3}$
}

\author{
${ }^{1}$ Associate Professor, Department of Forensic Medicine \& Toxicology, Konaseema Institute of Medical Sciences and Research \\ Foundation, Amalapuram. \\ ${ }^{2}$ Assistant Professor, Department of Forensic Medicine \& Toxicology, Rangaraya Medical College, Kakinad. \\ 3 Professor \& HOD, Department of Forensic Medicine \& Toxicology, Konaseema Institute of Medical Sciences and Research Foundation, \\ Amalapuram.
}

\begin{abstract}
Medico-legal age estimation is one of the tasks in clinical forensic medicine. In many instances, the courts of law seek medical opinion on the age of an individual. The circumstances may be civil, like to find the date of retirement in cases where the birth record is not available or criminal as in cases of child labour, juvenile delinquency, rape, kidnapping from lawful guardian, etc. There is a wide confusion and controversy regarding the standard method to be used for estimating age in the Indian Subcontinent. The aim of the current study is to find the correlation among the various parameters of commonly examined ossification centres, through which a regression formula with positive correlation and maximum coefficient of determination can be derived which can be attempted to be standardised for the estimation of age.
\end{abstract}

\section{KEYWORDS}

Medico-Legal Age Estimation, Ossification Centres, Regression Formula.

HOW TO CITE THIS ARTICLE: Rao GSRKGR, Kiran PP, Prasad GKV. Research on correlation among different ossification centres in female. J. Evolution Med. Dent. Sci. 2016;5(23):1238-1242, DOI: 10.14260/jemds/2016/289

\section{INTRODUCTION}

The medico-legal age estimation is based on the findings of physical examination, dental examination and radiological examination among which radiological examination of various ossification centres of bones form the back bone of the estimation.

There are hundreds of ossification centres in the bones of the human body. The appearance and fusion of some ossification centres in the bones form the basis of estimation of age.

For estimation of age of a person from bones, in the practical field, activities of different ossification centres in the pre-natal and post-natal period of life, up to the age of 20-22 years are given more weightage. In elderly subjects, skull vault suture closure, union activity of the sternum complex, changes in the shape of mandible, changes at the pubic symphysis and around glenoid cavity of scapula and general changes in the bones due to ageing are taken into account.[1]

According to Aggarwal MI and Pathak (1957).[2] epiphyses of bones unite during age periods, which are remarkably constant for a particular epiphysis. This is possible due to complex, but dependable system by which the osseous framework of the body develops, grows and matures. Epiphyses of the bones unite at a particular age and this is helpful in age determination.

Countable differences are noticed in the appearance and fusion activities of ossification centres depending on race, geographic distribution and sex.

Financial or Other, Competing Interest: None.

Submission 30-01-2016, Peer Review 02-03-2016,

Acceptance 07-03-2016, Published 19-03-2016.

Corresponding Author:

Dr. Golakoti Sree Rama Krishna Gangadhara Ranga Rao,

Associate Professor,

Department of Forensic Medicine,

Konaseema Institute of Medical Sciences and Research Foundation,

Amalapuram,

Andhra Pradesh.

E-mail:drgsrkgrrao@gmail.com

DOI: $10.14260 /$ jemds $/ 2016 / 289$
The process of ossification may be influenced by food habit, nutritional status, infectious diseases, hormonal and metabolic disorders and physical activity. Generally, ossification activities occur earlier in Indian population than in western population. The activities are generally earlier in females than in males.

With increase in the number of social litigation cases both in criminal as well as in civil side, a Forensic specialist is presently heavily burdened with cases of estimation of age. The members of the legal institution and the contesting parties, all expect that the doctor declares a specific age for the person he has examined. But it is well recognised fact that the age of an individual cannot be determined, but can only be estimated. Even our courts have acknowledged this point.

Many researchers paid attention to this subject and the different methods used for age estimation. The first persons to work on this issue were Pryor [1928].[3] who undertook studying the time of appearance of the ossification centres of the wrist and Krogman [1939] who studied time of epiphysis union.

Data on the union of epiphyses are much more frequently used in forensic anthropology, especially for the teenage years. Standards are available for the clavicle. ${ }^{[4]}$ hand and wrist. ${ }^{[5]}$ and knee.[6]

McKern and Stewart.[7] provided data on the union of a variety of epiphyses in their study of young American males who died in the Korean conflict. General summaries of these and other works are provided by Krogman. ${ }^{[8]}$ and Stewart. ${ }^{[9]}$

All of the works cited above except Stevenson.[10] have documented a marked sex difference in the timing of epiphyseal union. Lewis and Garn.[11] noted that in the appearance of 36 ossification centres, girls were advanced over boys by about $25 \%$.

The difference was about $19 \%$ in the timing of knee ossification. Data summarized by Krogman. [8] and Stewart.[9] show that union of most epiphyses occur in females about 1 to 2 years earlier than in males. 


\section{AIMS AND OBJECTIVES}

The aim of the current study is to find the correlation among the various parameters of commonly examined following ossification centres, through which a regression formula with positive correlation and maximum coefficient of determination can be derived, which can be attempted to be standardised for the estimation of age.

1. Tip of acromion.

2. Head of humerus.

3. Medial epicondyle.

4. Upper end of radius.

5. Lower end of radius.

6. Lower end of ulna.

7. Base of $1^{\text {st }}$ metacarpal.

8. Iliac crest.

9. Head of femur.

10. Greater trochanter.

\section{MATERIALS AND METHODS}

The present retrospective study is based on the examination of the radiographs of 300 individuals who were brought to the Department of Forensic Medicine, Rangaraya Medical College, Kakinada, for the purpose of Medico-legal age estimation during the academic years 2011-12, 2012-13 and 2013-14.

The ossification process is divided into the following 7 progressive stages [0-6], for which corresponding point scores were given.

The reference is made to the study done by Darmesh $\mathrm{S}$ Patel et al.[12] who studied "Epiphyseal fusion at lower end of radius and ulna-valuable tool for age determination, original research paper" and classified fusion process into 4 stages.

\section{Non-union}

A dark black radiolucent line seen between the area of diaphysis and epiphysis. This stage is labelled as stage 0 .

\section{Union in Progress}

Gap between diaphysis and epiphysis begins to decrease, but complete union does not occur. This stage is labelled as stage+.

\section{Complete Union with White Dense Line}

Union between diaphysis and epiphysis completed, but white dense line still visible at diaphysio-epiphyseal junction. This stage is labelled as stage ++ .

\section{Complete Union without Any Dense White Line}

Union between diaphysis and epiphysis and no white dense line visible at diaphysio-epiphyseal junction. This stage is labelled as stage +++ .

The published stages of fusion mentioned above are adopted in the present study. In addition, the process of appearance of an ossification centre has also been divided into 3 stages. An integration of both these resulted in a comprehensive staging ranging from stage $0-6$.

Thus, the stage of non-union or stage 1 of Darmesh $\mathrm{S}$ Patel classification of stages of fusion has become stage 3 in the comprehensive staging. Likewise stage 2 became stage 4 , stage 3 became stage 5 and stage 4 became stage 6 of the present study.

\begin{tabular}{|c|c|c|}
\hline Stage & Ossification Process & Point Score \\
\hline 0 & Ossification centre not appeared & 0 \\
\hline 1 & $\begin{array}{c}\text { Ossification centre just appeared } \\
\text { like white spots }\end{array}$ & 1 \\
\hline 2 & $\begin{array}{c}\text { Expansion of ossification centre } \\
\text { up to half of full extent }\end{array}$ & 2 \\
\hline 3 & $\begin{array}{c}\text { Expansion of ossification to the } \\
\text { full extent }\end{array}$ & 4 \\
\hline 4 & $\begin{array}{c}\text { Narrowing of gap between } \\
\text { epiphysis and diaphysis }\end{array}$ & 5 \\
\hline 5 & $\begin{array}{c}\text { Complete union of epiphysis and } \\
\text { diaphysis with dense white line }\end{array}$ & 6 \\
\hline 6 & $\begin{array}{c}\text { Complete union of epiphysis and } \\
\text { diaphysis without any white line }\end{array}$ & \\
\hline \multicolumn{3}{|c|}{ Table 1: Staging and Point Score } \\
System of the Ossification Process \\
\hline
\end{tabular}

Total point score is calculated by adding point scores of all the ten ossification centres in a particular case. Later the data is subjected to statistical analysis to calculate the correlation coefficient [p] for goodness of correlation between the total point score and the age of the individual.

Correlation coefficient [p]: $\mathrm{N} \sum \mathrm{XY}-\left(\sum \mathrm{X}\right) \quad\left(\sum \mathrm{Y}\right) / \sqrt{ }\left(\left[\mathrm{N}^{2} \mathrm{X}^{2}{ }^{-}\right.\right.$ $\left.\left(\sum \mathrm{X}\right)^{2}\right]\left[\mathrm{N} \sum \mathrm{Y}^{2}-\left(\sum \mathrm{Y}^{2}\right]\right)$

Where,

$\mathrm{N}=$ number of cases

$\mathrm{X}=$ total point score

$\mathrm{Y}=$ age in years. Later, a graph is plotted with age [in years] on $\mathrm{Y}$-axis and total point scores on $\mathrm{X}$-axis for the goodness of regression formula.

Regression equation $(\mathrm{y})=\mathrm{A}+\mathrm{Bx}$, Where $\mathrm{x}$ and $\mathrm{y}$ are variables. Slope $(\mathrm{B})=\left[\mathrm{N} \sum \mathrm{XY}-\left(\sum \mathrm{X}\right)\left(\sum \mathrm{Y}\right)\right] /\left[\mathrm{N} \sum \mathrm{X}^{2}-\left(\sum \mathrm{X}\right)^{2}\right]$

Intercept $(\mathrm{A})=[\Sigma \mathrm{Y}-\mathrm{B}(\mathrm{X})] / \mathrm{N}$

Where,

$\mathrm{N}=$ number of cases

$\mathrm{X}=$ total point score

$\mathrm{Y}=$ age in years

\section{RESULTS}

\begin{tabular}{|c|c|c|c|}
\hline Gender & Males & Females & Total \\
\hline No. of Cases & 64 & 236 & 300 \\
\hline \% of Cases & $21 \%$ & $79 \%$ & $100 \%$ \\
\hline \multicolumn{2}{|c|}{ Table 2: Sex Wise Distribution of Study Subjects } \\
\hline
\end{tabular}

\begin{tabular}{|c|c|c|}
\hline Sl. No. & Age Group & No. of Cases \\
\hline 1 & 14 & 8 \\
\hline 2 & $14-15$ & 3 \\
\hline 3 & 15 & 7 \\
\hline 4 & $15-16$ & 15 \\
\hline 5 & 16 & 28 \\
\hline 6 & $16-17$ & 43 \\
\hline 7 & 17 & 45 \\
\hline 8 & $17-18$ & 21 \\
\hline 9 & 18 & 19 \\
\hline 10 & $18-19$ & 11 \\
\hline 11 & 19 & 16 \\
\hline 12 & $19-20$ & 5 \\
\hline 13 & 20 & 7 \\
\hline 14 & $20-21$ & - \\
\hline 15 & 21 & 1 \\
\hline 16 & $21-22$ & 2 \\
\hline 17 & 22 & 2 \\
\hline 18 & $22-23$ & 2 \\
\hline 19 & 23 & 1 \\
\hline \multicolumn{2}{|c|}{ Total no. of Cases } & $\mathbf{2 3 6}$ \\
\hline Table 3: Age Wise Distribution of Female Study Subjects \\
\hline \multicolumn{2}{|r}{}
\end{tabular}




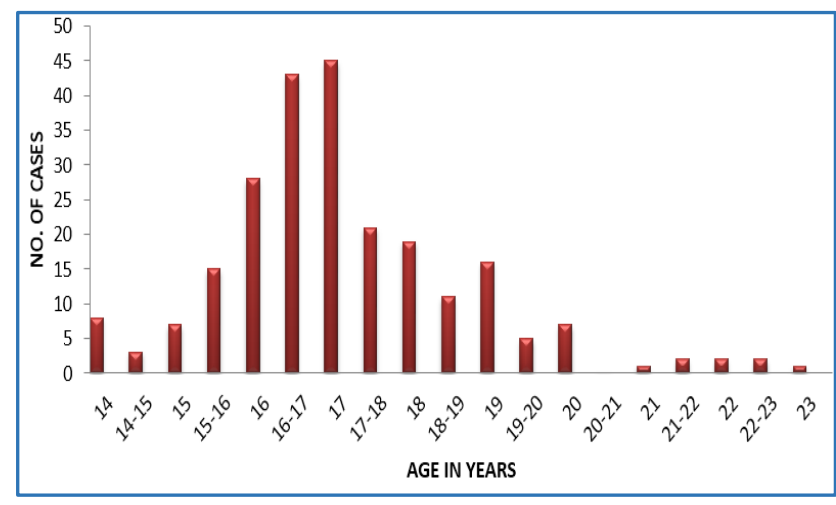

Chart 1: Age Wise Distribution of Female Study Subjects

\begin{tabular}{|c|c|c|}
\hline Sl. No. & Age Group & Total Point Score \\
\hline 1 & 14 & 36.75 \\
\hline 2 & $14-15$ & 41.33 \\
\hline 3 & 15 & 44.42 \\
\hline 4 & $15-16$ & 48.73 \\
\hline 5 & 16 & 51.25 \\
\hline 6 & $16-17$ & 55.90 \\
\hline 7 & 17 & 57.22 \\
\hline 8 & $17-18$ & 58.23 \\
\hline 9 & 18 & 59 \\
\hline 10 & $18-19$ & 59 \\
\hline 11 & 19 & 60 \\
\hline 12 & $19-20$ & 60 \\
\hline 13 & 20 & 60 \\
\hline 14 & $20-21$ & 60 \\
\hline 15 & 21 & 60 \\
\hline 16 & $21-22$ & 60 \\
\hline 17 & 22 & 60 \\
\hline 18 & $22-23$ & 60 \\
\hline 19 & 23 & 60 \\
\hline Table 4: Aggregate List of Total Point Scores in Females \\
\hline \multicolumn{2}{|c}{}
\end{tabular}

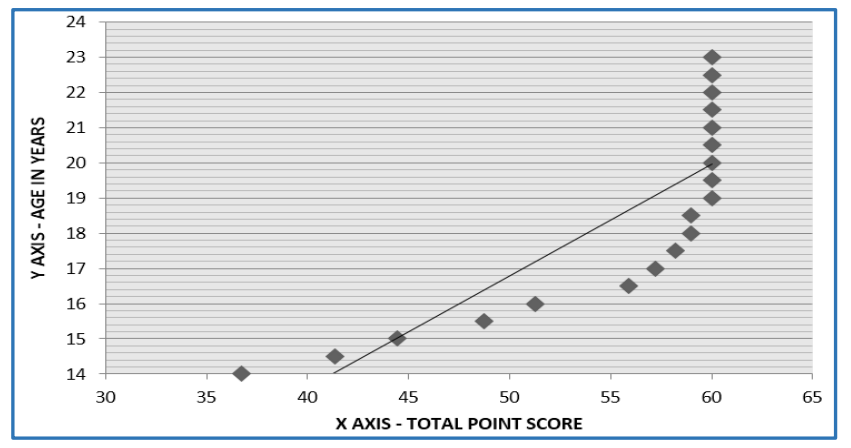

Chart 2: Regression Graph for Age Group 14 to 23 Years in Females

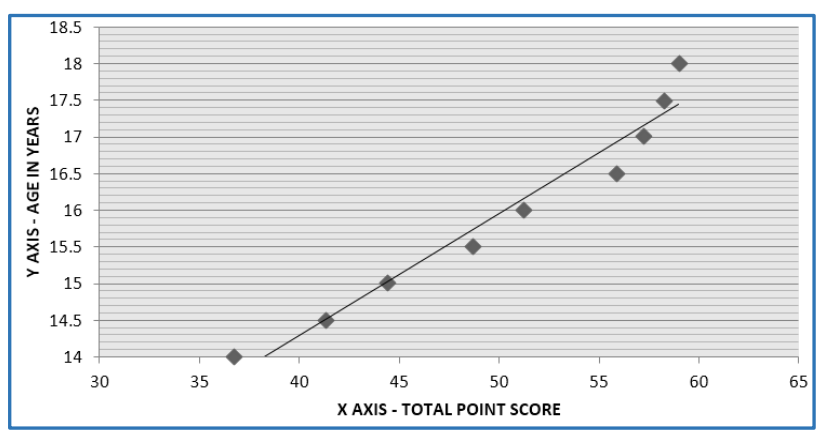

Chart 3: Regression Graph for Age Group 14 to 18 Years in Females

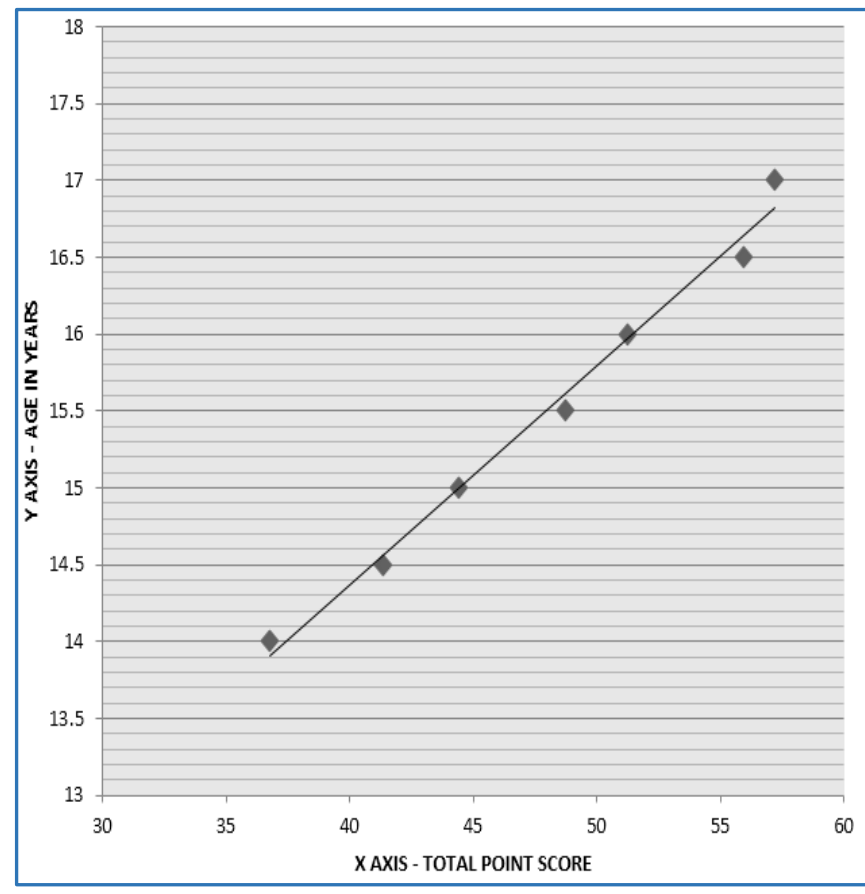

Chart 4: Regression Graph for Age Group 14 to 17 Years in Females

\section{DISCUSSION}

Among the selected 300 study subjects, 64 [i.e. 21\%] are male and 236 [i.e. 79\%] are female. Among females, ages of the study subjects ranged from 14 years to 23 years, significant number of subjects belonged to the age group between 14 and 18 years [80.1\%].

Calculation of the correlation coefficient and the coefficient of determination between the age estimated as per the standard method and the total point score, obtained through a series of calculations done after grading the stages of appearance and fusion of ossification centres is done.

The correlation coefficient and R-squared $\left(\mathrm{R}^{2}\right)$ values depict the relationship between two data series and how well the model predicts the future outcomes. Pearson's formula is used for this calculation.

Correlation coefficient is a measure of the strength of linear association between two variables. Correlation will always be between -1.0 and +1.0 . If the correlation is positive, we have a positive relationship. If it is negative, the relationship is negative.

\section{Among the Females,}

- When all the available age groups are taken into consideration for the study

- $\quad$ Correlation coefficient [p] : 0.824

- When the study is limited to the age group 14-18 years, which has significant sample size [i.e. $>75 \%$ ]

- $\quad$ Correlation coefficient [p] : 0.976

- When the study is limited to the age group 14-17 years

- $\quad$ Correlation coefficient [p] : 0.994

A positive correlation between age and the total point score is observed

- Maximum correlation is seen in the age group 14-17 years, followed by age group 14-18 and least in age group 14-23 years. 


\begin{tabular}{|c|c|}
\hline Age Group [In Years] & Correlation Coefficient [p] \\
\hline 14 to 23 & 0.824 \\
\hline 14 to 18 & 0.976 \\
\hline 14 to 17 & 0.994 \\
\hline \multicolumn{2}{|c|}{ Table 5: Correlation Coefficients for Various } \\
Age Groups in Females \\
\hline
\end{tabular}

A regression is a statistical analysis assessing the association between two variables. It is used to find the relationship between two variables. In statistics, the coefficient of determination denoted $\mathrm{R}^{2}$ and pronounced $\mathrm{R}$ squared, indicates how well data points fit a line or curve. It is a statistic used in the context of statistical models whose main purpose is either the prediction of future outcomes or the testing of hypotheses, on the basis of other related information. It provides a measure of how well observed outcomes are replicated by the model, as the proportion of total variation of outcomes explained by the model.

$\mathrm{R}^{2}$ is a statistic that will give some information about the goodness of fit of a model. In regression, the $\mathrm{R}^{2}$ coefficient of determination is a statistical measure of how well the regression line approximates the real data points. An $\mathrm{R}^{2}$ of 1 indicates that the regression line perfectly fits the data.

\section{Among the Females,}

- When all the available age groups are taken into consideration for the study,

- Regression formula: $y=0.318 x+0.886$

\section{Where $y=$ age in years, $x=$ total point score}

- Coefficient of determination [R²]: 0.679

- When the study is limited to the age group 14-18 years, which has significant sample size [i.e. $>75 \%$ ]

- Regression formula: $y=0.165 x+7.653$

\section{Where $y=$ age in years, $x=$ total point score}

- Coefficient of determination [R²]: 0.953

- When the study is limited to the age group 14-17 years

- Regression formula: $\mathrm{y}=1.42 \mathrm{x}+8.681$

\section{Where $y=$ age in years, $x=$ total point score}

- Coefficient of determination [R2]: 0.989

Among the regression formulae derived, the formula that was obtained for the age group 14-17 years has the maximum coefficient of determination.

\begin{tabular}{|c|c|c|}
\hline $\begin{array}{c}\text { Age Group } \\
\text { [In years] }\end{array}$ & $\begin{array}{c}\text { Coefficient of } \\
\text { Determination } \\
{\left[\mathbf{R}^{2}\right]}\end{array}$ & $\begin{array}{c}\text { Regression } \\
\text { Formula }\end{array}$ \\
\hline 14 to 23 & 0.679 & $\mathrm{Y}=0.318 \mathrm{x}+0.886$ \\
\hline 14 to 18 & 0.953 & $\mathrm{Y}=0.165 \mathrm{x}+7.653$ \\
\hline 14 to 17 & 0.989 & $\mathrm{Y}=1.42 \mathrm{x}+8.681$ \\
\hline $\begin{array}{c}\text { Table 6: Coefficients of Determination and Regression } \\
\text { Formulae for Various Age Groups in Females }\end{array}$ \\
\hline
\end{tabular}

- This implies that the age calculated by the regression formula derived for the age group 14-17 years is the nearest possible value to the age calculated by the standard method.
- Hence, only the ages between 14 and 17 years can only be estimated precisely using the above derived regression formula.

- Because of the limited scope of this study involving only limited number of ossification centres, which are significant to a particular age group. The regression formulae derived will not be applicable to estimate the age beyond the age group 14 to 17 years in females.

\section{CONCLUSION}

This is a humble effort to experiment a point score system in age estimation. The study is about the correlation between the age estimated as per the standard method and the total point score obtained through a series of calculations done after grading the stages of appearance and fusion of ossification centres. The focus was on the secondary centres of ossification. This study depicted a linear positive correlation among the above considered parameters. In females, maximum correlation was observed in the age group between 14 and 17 years. An attempt was made to derive a regression formula that can be used to estimate age. Because of the limited scope of this study involving only limited number of ossification centres which are significant to a particular age group, the regression formulae thus derived cannot be applied to estimate the age beyond the age group 14 to 18 years in males and 14 to 17 years in females.

It is our hope that this attempt may stimulate further work in the area leading to further enlightenment.

\section{RADIOGRAPHS}

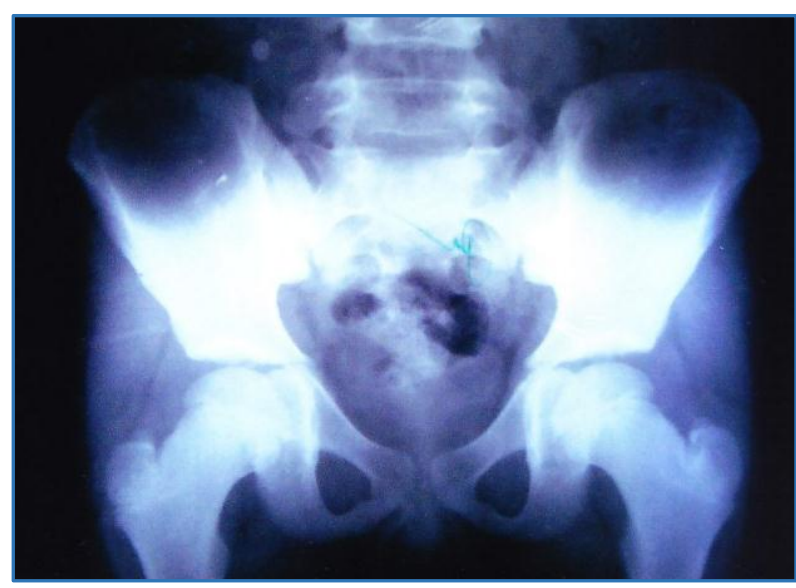

Radiograph 1: Iliac Crest - Stage 0

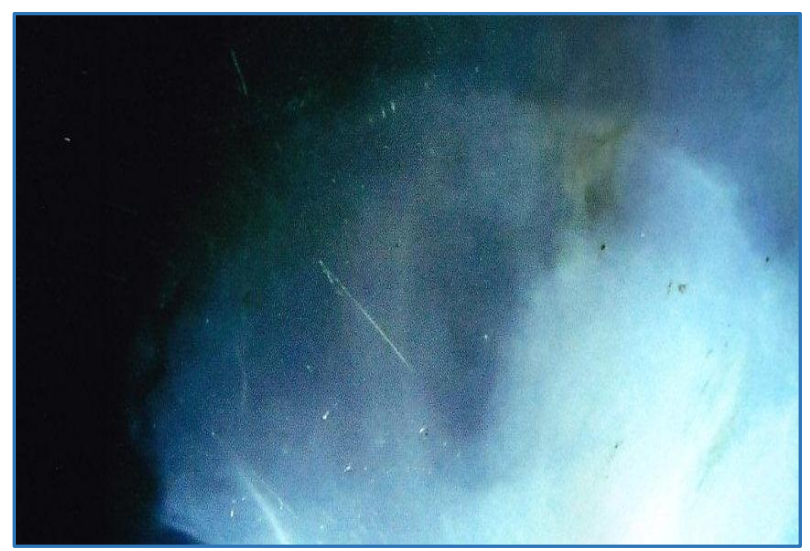

Radiograph 2: Iliac Crest - Stage 1 


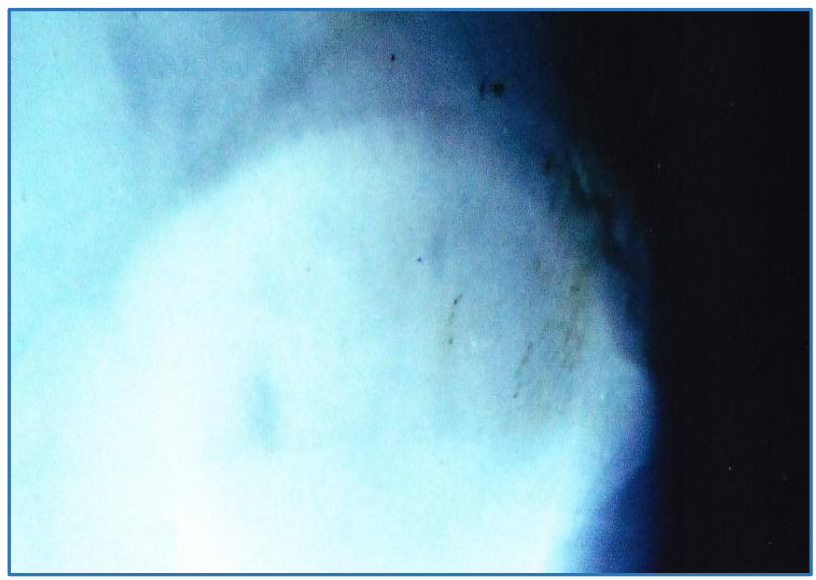

Radiograph 3: Iliac Crest - Stage 2

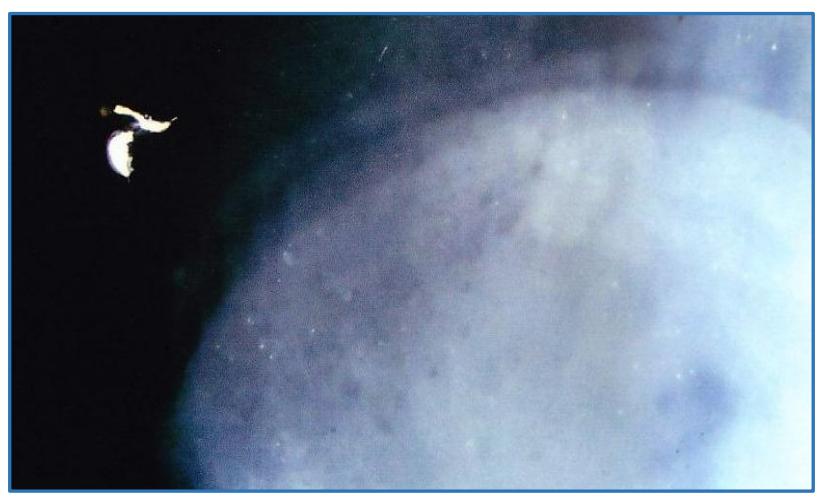

Radiograph 4: Iliac Crest - Stage 3

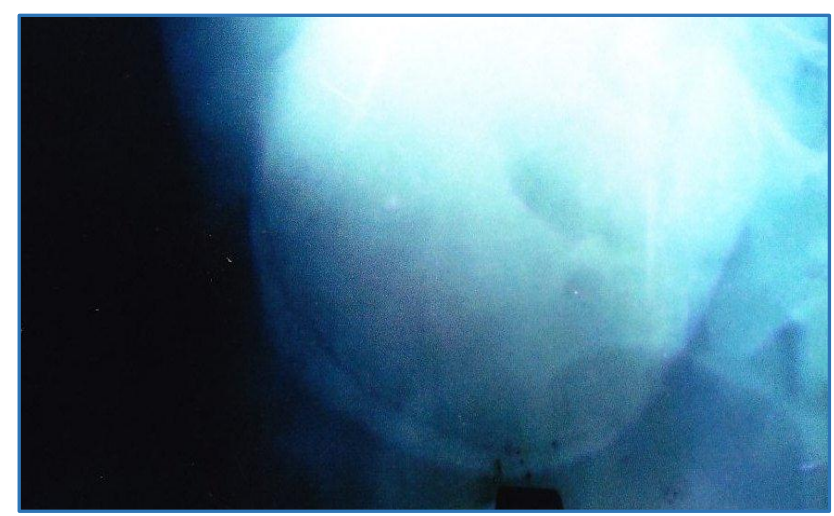

Radiograph 5: Iliac Crest - Stage 4

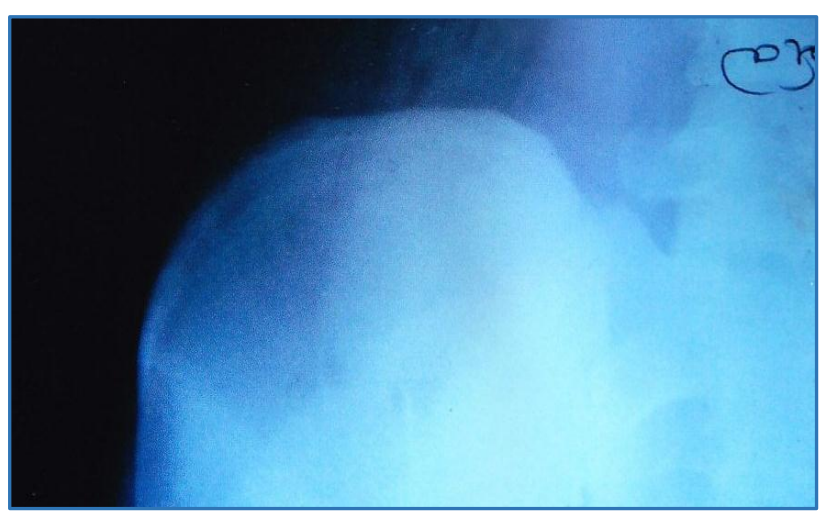

Radiograph 6: Iliac Crest - Stage 5

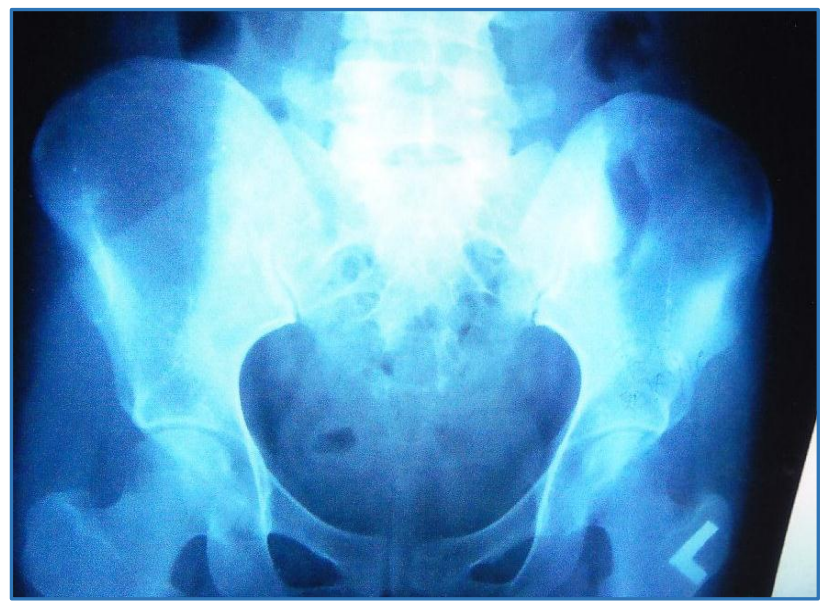

Radiograph 7: Iliac Crest - Stage 6

\section{ACKNOWLEDGEMENTS}

Sincere thanks for the guidance of Dr. G. K. V. Prasad MBBS., MD [FM\&T] Professor and Head Department of Forensic Medicine and Toxicology, Konaseema Institute of Medical Sciences, Amalapuram, Andhra Pradesh.

\section{REFERENCES}

1. Nandy, Apurba. Principles of forensic medicine including Toxicology. 2010;3 $3^{\text {rd }}$ Edition:119-123 and 145-147.

2. Aggarwal ML, Pathak IC. Roentgenologic study of epiphyseal union in punjabi girls for determination of age. Ind j med res 1957;45(2):283-289.

3. Williams, Pryor James Sl. Some observations on the ossification of the bones of the hand. Lexington University press.

4. Todd TW, D'Errico J. The clavicular epiphyses. the american journal of anatomy 1928;41:25-50.

5. Greulich WW, Pyle S. Radiographic atlas of skeletal development of the hand and wrist. 1950.

6. Pyle SI, Hoerr NL. Radiographic atlas of skeletal development of the knee. 1955.

7. Kern TW, Stewart. Skeletal changes in young american males, analysed from the standpoints of age identification. 1957.

8. Krogman, Wilton Marion. The human skeleton in forensic medicine. 1939;2nd Edition.

9. Stewart TD. Essentials of forensic anthropology, especially as developed in the united sates. 1979.

10. Stevenson PH. Age order of epiphyseal union in man. american journal of physical anthropology 1924;7(1):53-93.

11. Lewis $\mathrm{AB}$, Garn $\mathrm{S}$. The relationship between tooth formation and other maturational factors. the angle orthodontist 1960;30(2):70-77.

12. Darmesh S Patel, Harish Agarwal, Jigesh V Shah. Epiphyseal fusion at lower end of radius and ulna a valuable tool for age determination. JIAFM 2011;33(2):125-129. 